\title{
MONTE CARLO SIMULATION IN INTRALOGISTICS
}

\author{
Branko Davidović \\ Technical High School, Kragujevac, Serbia \\ Duško Letić \\ University of Novi Sad, Faculty of Technical Sciences, Zrenjanin, Serbia \\ Aleksandar Jovanović \\ University of Belgrade, Faculty of transport and traffic engineering, Belgrade
}

() MESTE NGO

JEL code: C02, C15, C6, C63

\begin{abstract}
One of the tasks of the intralogistics services is to help the development of the production process timely, i.e. to provide the continuity of production. This requires, among other things, the harmonization of production rhytms and the transporting-manipulative equipments' work cycles. In them, the process of transport runs and is organized so the material is delivered to work positions two to four hours before the processing starts, and taken away two to eight hours after the processing has been finished. This analysis has multiple aims. First, we should determine which number of transporting equipments would minimize the total costs. Further, when making this decision, we don't want to experiment in reality but on the model, in advance, before engaging ourselves in investments, i.e. before the transport has been realised and the technology and the organization of the working system engaged. In that respect, our aim is to shape and analyze more and less expensive variants of the solution with relatively short realization deadlines. Finally, we need a procedure which will be accessible and useful to the project engineers of the technological and transporting processes in intralogistics.
\end{abstract}

Key words: intralogistics, simulation, modelling, algorithm, work cost, variant

\section{INTRODUCTION AND PROBLEM DEFINING}

One of the main tasks of the intralogistics services is to support development of the production process, i.e. to provide continuity of production, (Davidović, 2012)which requires, also, the harmonization of production rhytms and

The address of the corresponding author:

\section{Branko Davidović}

奉= iwtbg@beotel.net the transporting-manipulative equipments' work cycles. The examined problem will be simplified by the experimental fact that there exist variations in the daily extent of output, and, consequently, in the daily volume of the transport tasks which have been realized. If we determine the quantity of the means of transport on the basis of maximum needs, according to the maximum daily production (which is recorded very few times during the year), in this case the car fleet will expose us to relatively high investment and maintenance costs. Besides, 
during most of the year we won't be able to use the available transport capacities completely. On the other hand, if we take a smaller number of equipments than the one corresponding the transport tasks with the maximum daily production, the loss of the transport capacity, which needs be compensated by overtime work, will occasionally appear. However, less equipments mean smaller investment and maintenance costs. So, we can see that the number of equipments implies two types of reverse trends. More equipments mean the rise of investment and maintenance costs, but the decline of the extra work costs.

Less equipments bring the reduction of the investment and maintenance costs, but the increase of the overtime work costs.

\section{CONCEPTION AND METHODS FOR THE PROBLEM SETTLEMENT}

The problem considered can be solved by Monte Carlo numerical simulation [ (Fishman, 1999), (Kun, 1973), (Vukadinović \& Popović, 1996)]. Therefore, it is necessary to collect the parameters needed for setting the simulation model. As first, it is necessary to establish the distribution of frequency according to the daily material demand $\left(\mathrm{kg}, \mathrm{pcs}, \mathrm{m}^{3} \ldots\right)$, to be transported, by using the variations.of the daily volume of production. Then, the distribution of frequency of the daily material delivery per one means should be established. We also need the information about the amortization, maintenance and exploitation of means. Further on, the personal incomes of transport workers as well as the overtime work expenses should be determined. Other data, which also influence the problem considered, can be introduced. The problem was considered in a metal processing factory which had the arranged data about the daily scope of production and about the movement of the daily demand and material delivery from the previous period.

These data will be used in all the future analyses and they will be completed by the supposition that the production situation is stable. In other words, it is necessary for the developments in the plant to be realized according to the probability laws which were valid in the previous period. In that respect, the company analysts placed the following data at our disposal:

The distribution of frequency the daily demand follows the law of normal distribution, with:

- the average value of: $U_{s}=300$ loads/day;

- the standard deviation of: $\sigma_{1}=20$ loads/day.

The distribution of frequency of the daily delivery of load also follows the normal distribution, but with:

- the average value of: $v=40$ loads/day;

- the standard deviation of: $\sigma_{2}=4$ loads/day.

All costs of the transport facilities exploitation, including the personal incomes are:

$$
t=200 \text { monet.units/day/per vehicle. }
$$

All the costs of the equipments exploitation during the overtime work, including personal incomes, are:

$$
D=30 \text { monet.units/hour/per vehicle. }
$$

By using the previous data, we can start solving the problem. The basic conception is that the daily demand, as well as the daily delivery of load and the mass operating phenomena, each in its own way, depend on the multitude of factors and their interactions, that is, both phenomena depend on luck. According to that, this phenomenon can be considered through the law of probability, that is, through the mathematical statistics.

\section{THE DEVELOPMENT OF THE SIMULATION MODEL}

We start the analysis by considering the distribution of frequency of the daily quantity of material, that is, of the average value and the standard deviation of that distribution. But, instead of observing the movement of that demand, i.e. the movement depending on luck, in reality from day to day, those cases will be simulated here, as presented in the following tables. We perform the simulation by connecting each development, in this case the daily demand of material, with a random number. In other words, if these plant occurences appear 'accidentally', that can happen in the same way that some numbers appear randomly. They can be generated by computer [ (Letić, Davidović, 
Berković, \& Petrov, 2007), (Pidd, 1998), (Radenković, Stanojević, \& Marković, 1999)]. For this type of simulation we need random numbers with average value Us $=300$ and:

- the total deviation of daily demand of:

$$
6 \cdot \sigma_{1}=120
$$

- the average value of $v=60$ and the total deviation with the daily delivery: $6 \cdot \sigma_{2}=24$

We need this type of random numbers because we can find the standard deviations $\sigma_{1}$ and $\sigma_{2}$ of the statistical sets among the initial data, supposing that the total deviation, as the maximum deviation spread, equals six sigma.

\subsection{Simulation of demand of the daily quantity of load}

We perform the demand simulation of the daily quantity of load for one working week, considering that it consists of five working days $\mathrm{T}-1$. The simulation algorithm is so shaped that from the average value of demand, i.e. from Us $=300$, we substract or we add the value of accidental deviation to that value.

Table 1 The simulation of the daily quantity of load during one working week (T-1)

\begin{tabular}{|c|}
\hline Ua \\
\hline 288.115 \\
\hline 271.8 \\
\hline 341.813 \\
\hline 308.98 \\
\hline
\end{tabular}

The random number 3 -rnd (6) can have the highest value of +3 , the smallest -3 , and it is uniformly distributed.

The simulation model can be presented as:

$a:=1 \ldots 5 \quad \mathrm{U}_{\mathrm{a}}:=\mathrm{U}_{\mathrm{s}}+\sigma_{1} \cdot(3-\mathrm{md}(6))$

3.2 Simulation of delivery of the daily quantity of load

The simulation of the daily transported material quantity during one working week is presented in the tables (T-2/8). We can perform the simulation in many variants, i.e. for the case of one, two or more means. Therefore, the number of means $(n)$ is the parameter that can be changed, e.g. as: $n=1.6$

The algorithm and the simulation flow are similar to the previous one: $V_{a}=v+\sigma_{1} \cdot(3-r n d(6))$.

Let's generate one series of random numbers 3rnd(6), one number for each working day. This series of numbers should differ from the adequate series at daily demand, because the daily transported material quantities are distributed differently. However, the series of five random numbers should be kept in all variants of the transport simulation, so they could be compared mutually.

Table 2 The simulation of the daily transported material quantity during one working week

\begin{tabular}{|c|c|c|c|c|c|}
\hline $\mathrm{V}_{\mathrm{a}}$ & $2 \mathrm{~V}_{\mathrm{a}}$ & $3 \mathrm{~V}_{\mathrm{a}}$ & $4 \mathrm{~V}_{\mathrm{a}}$ & $5 \mathrm{~V}_{\mathrm{a}}$ & $6 \mathrm{~V}_{\mathrm{a}}$ \\
\hline 68.010 & 136.020 & 204.030 & 272.040 & 340.050 & 408.060 \\
\hline 61.181 & 122.362 & 183.543 & 244.724 & 305.905 & 367.086 \\
\hline 70.631 & 141.262 & 211.893 & 282.524 & 353.155 & 423.786 \\
\hline 53.200 & 106.400 & 159.600 & 212.800 & 266.000 & 319.200 \\
\hline 59.523 & 119.046 & 178.569 & 238.092 & 297.615 & 357.138 \\
\hline
\end{tabular}

We keep these five random numbers in all variants - for the variant of work simulation with one vehicle, two equipments, three equipments, etc. up to the sixth vehicle.
Table 3 The variant of work simulation with one vehicle

\begin{tabular}{|c|c|c|}
\hline$U_{a}$ & $V_{a}$ & $U_{a}-V_{a}$ \\
\hline 288.115 & 67.296 & 220.819 \\
\hline 271.800 & 51.854 & 219.946 \\
\hline 291.312 & 59.978 & 231.334 \\
\hline 341.813 & 71.340 & 270.473 \\
\hline 308.980 & 58.258 & 250.722 \\
\hline
\end{tabular}


Table 4 The variant of work simulation with two equipments

\begin{tabular}{|c|c|c|}
\hline $\mathrm{U}_{\mathrm{a}}$ & $2 \mathrm{~V}_{\mathrm{a}}$ & $\mathrm{U}_{\mathrm{a}}-2 \mathrm{~V}_{\mathrm{a}}$ \\
\hline 288.115 & 134.592 & 153.523 \\
\hline 271.800 & 103.708 & 168.092 \\
\hline 291.312 & 119.956 & 171.356 \\
\hline 341.813 & 142.680 & 199.133 \\
\hline 308.980 & 116.516 & 192.464 \\
\hline
\end{tabular}

Table 5 The variant of work simulation with tree equipments

\begin{tabular}{|c|c|c|}
\hline $\mathrm{U}_{\mathrm{a}}$ & $3 \mathrm{~V}_{\mathrm{a}}$ & $\mathrm{U}_{\mathrm{a}}-3 \mathrm{~V}_{\mathrm{a}}$ \\
\hline 288.115 & 201.888 & 86.227 \\
\hline 271.800 & 155.562 & 116.238 \\
\hline 291.312 & 179.934 & 111.378 \\
\hline 341.813 & 214.02 & 127.793 \\
\hline 308.980 & 174.774 & 134.206 \\
\hline
\end{tabular}

Table 6 The variant of work simulation with four equipments

\begin{tabular}{|c|c|c|}
\hline $\mathrm{U}_{\mathrm{a}}$ & $4 \mathrm{~V}_{\mathrm{a}}$ & $\mathrm{U}_{\mathrm{a}}-4 \mathrm{~V}_{\mathrm{a}}$ \\
\hline 288.115 & 269.184 & 18.931 \\
\hline 271.800 & 207.416 & 64.384 \\
\hline 291.312 & 239.912 & 51.400 \\
\hline 341.813 & 285.360 & 56.453 \\
\hline 308.980 & 233.032 & 75.948 \\
\hline
\end{tabular}

Table 7 The variant of work simulation with five equipments

\begin{tabular}{|c|c|c|}
\hline $\mathrm{U}_{\mathrm{a}}$ & $5 \mathrm{~V}_{\mathrm{a}}$ & $\mathrm{U}_{\mathrm{a}}-5 \mathrm{~V}_{\mathrm{a}}$ \\
\hline 288.115 & 336.480 & -48.365 \\
\hline 271.800 & 259.270 & 12.530 \\
\hline 291.312 & 299.890 & -8.578 \\
\hline 341.813 & 356.700 & -14.887 \\
\hline 308.980 & 291.290 & 17.690 \\
\hline
\end{tabular}

Table 8 The variant of work simulation with six equipments

\begin{tabular}{|c|c|c|}
\hline $\mathrm{U}_{\mathrm{a}}$ & $6 \mathrm{~V}_{\mathrm{a}}$ & $\mathrm{U}_{\mathrm{a}}-6 \mathrm{~V}_{\mathrm{a}}$ \\
\hline 288.115 & 403.776 & -115.661 \\
\hline 271.800 & 311.124 & -39.324 \\
\hline 291.312 & 359.868 & -68.556 \\
\hline 341.813 & 428.040 & -86.227 \\
\hline 308.980 & 349.548 & -40.568 \\
\hline
\end{tabular}

3.3 The simulation of the overtime work costs

In the next phase, we perform the simulation of the overtime work costs, as shown in the next tables. Those costs were presented depending on the number of the assets employed, i.e. the earmarked assets. In the columns of these tables there are the data of the daily demand of material which were established in the table $T(9 / 14)$ by simulating. The values of the daily demand of material, as a series of numbers, remain unchanged for all variants, i.e. regardless of the number of means. The difference between the daily demand and the daily delivery of material presents the number of materials which should be transported by the extra work. It is presented in the tables $U_{a}-n \cdot V_{a}$. As we know that during one overtime hour one vehicle can deliver, on the average, eight materials/hour (which is derived from: 60 /materials/shift/vehicle/: $\quad 7,5$ hour/shift/ $=8$ materials/hour/vehicle), the necessary number of the extra work times is calculated by dividing the value of the column $G_{a}$ with eight, or by its multiplying by 0,125 , which has actually been done in the paper. We calculated the overtime work costs for every day by multiplying the extra work hours with the values gained from the analysts in advance, i.e. with $D=50$ monet.units/hour. These costs are shown in the following tables.

For every working week the daily costs of the extra work are added, and they are presented in the last column. The simulation has been performed for all six variants (Table 9 - Table 15), along with the application of the programme instruction if, so that we can dissociate ourselves from the negative value of the costs. 
Davidović, Letić \& Jovanović. Monte Carlo simulation in intralogistics MEST Journal Vol.2 No.1 pp.87-93

Table 9 The model

$$
\begin{array}{ll}
G 1_{a}:=U_{a}-1 \cdot V_{a} & G 1_{a}:=\text { if }\left(U_{a}-1 \cdot V_{a}<0,0, G 1_{a}\right) \\
G 2_{a}:=U_{a}-2 \cdot V_{a} & G 2_{a}:=\text { if }\left(U_{a}-2 \cdot V_{a}<0,0, G 2_{a}\right) \\
G 3_{a}:=U_{a}-3 \cdot V_{a} & G 3_{a}:=\text { if }\left(U_{a}-3 \cdot V_{a}<0,0, G 3_{a}\right) \\
G 4_{a}:=U_{a}-4 \cdot V_{a} & G 4_{a}:=\text { if }\left(U_{a}-4 \cdot V_{a}<0,0, G 4_{a}\right) \\
G 5_{a}:=U_{a}-5 \cdot V_{a} & G 5_{a}:=\text { if }\left(U_{a}-5 \cdot V_{a}<0,0, G 5_{a}\right) \\
G 5_{a}:=U_{a}-5 \cdot V_{a} & G 6_{a}:=\text { if }\left(U_{a}-6 \cdot V_{a}<0,0, G 6_{a}\right)
\end{array}
$$

Table 10 The simulation - variant 1

\begin{tabular}{|c|c|c|}
\hline $\mathrm{G}_{\mathrm{a}}$ & $0.125 \cdot \mathrm{G} 1_{\mathrm{a}}$ & $\mathrm{D} \cdot 0.125 \cdot \mathrm{G} 1_{\mathrm{a}}$ \\
\hline 220.819 & 27.602 & 828.071 \\
\hline 219.946 & 27.493 & 824.798 \\
\hline 231.334 & 28.917 & 867.503 \\
\hline 270.473 & 33.809 & 1014.274 \\
\hline 250.722 & 31.340 & 940.208 \\
\hline \multicolumn{3}{|c|}{$k_{1}=\sum_{a} D \cdot 0,125 \cdot G 1_{a}$}
\end{tabular}

Table 11 The simulation - variant 2

\begin{tabular}{|c|c|c|}
\hline $\mathrm{G} 2_{\mathrm{a}}$ & $0.125 \cdot \mathrm{G} 2_{\mathrm{a}}$ & $\mathrm{D} \cdot 0.125 \cdot \mathrm{G} 2_{\mathrm{a}}$ \\
\hline 153.523 & 19.190 & 575.711 \\
\hline 168.092 & 21.012 & 630.345 \\
\hline 171.356 & 21.420 & 642.585 \\
\hline 199.133 & 24.892 & 746.749 \\
\hline 192.464 & 24.058 & 721.740 \\
\hline
\end{tabular}

$$
k_{2}=\sum_{a} D \cdot 0,125 \cdot G 2_{a}
$$

Table 12 The simulation - vaiant 3

\begin{tabular}{|c|c|c|}
\hline G3a & $0.125 \cdot G 3 a$ & $D \cdot 0.125 \cdot G 3 a$ \\
\hline 86.228 & 10.7785 & 323.355 \\
\hline 116.238 & 14.52975 & 435.8925 \\
\hline 111.378 & 13.92225 & 417.6675 \\
\hline 127.793 & 15.974125 & 479.22375 \\
\hline 134.205 & 16.775625 & 503.26875 \\
\hline \multicolumn{3}{|c|}{$k_{3}=\sum_{a} D \cdot 0,125 \cdot G 3_{a}$}
\end{tabular}

Table 13 The simulation - vaiant 4

\begin{tabular}{|c|c|c|}
\hline $\mathrm{G} 4 \mathrm{a}$ & $0.125 \mathrm{G} 4 \mathrm{a}$ & $\mathrm{D}^{*} 0.125 \mathrm{G} 4 \mathrm{a}$ \\
\hline 18.932 & 2.367 & 70.995 \\
\hline 64.385 & 8.048 & 241.444 \\
\hline 51.4 & 6.425 & 192.750 \\
\hline 56.453 & 7.057 & 211.699 \\
\hline 75.947 & 9.493 & 284.801 \\
\hline
\end{tabular}

$$
k_{4}=\sum_{a} D \cdot 0,(2) 5 \cdot G 4_{a}
$$

Table 13 The simulation - vaiant 5

\begin{tabular}{|c|c|c|}
\hline G5a & $0.125 \cdot G 5 a$ & $D \cdot 0.125 \cdot G 4 a$ \\
\hline 0.00 & 0.00 & 0.00 \\
\hline 12.53 & 1.57 & 46.99 \\
\hline 0.00 & 0.00 & 0.00 \\
\hline 0.00 & 0.00 & 0.00 \\
\hline 17.69 & 2.21 & 66.33 \\
\hline \multicolumn{3}{|c|}{$k_{5}=\sum_{a} D \cdot 0$, (8) $5 \cdot G 5_{a}$}
\end{tabular}

Table 15 The simulation - variant 6

\begin{tabular}{|c|c|c|}
\hline G6a & $0.125 \cdot G 6 a$ & $D \cdot 0.125 \cdot G 6 a$ \\
\hline 0 & 0 & 0 \\
\hline 0 & 0 & 0 \\
\hline 0 & 0 & 0 \\
\hline 0 & 0 & 0 \\
\hline 0 & 0 & 0 \\
\hline \\
$k_{6}=\sum_{a} D \cdot 0,125 \cdot\left({ }^{9}\right)_{a}$ \\
\hline
\end{tabular}




\section{Davidović, Letić \& Jovanović. Monte Carlo simulation in intralogistics}

MEST Journal Vol.2 No.1 pp.87-93

\subsection{Calculation of the total transport expenses}

The total expenses are presented as all the others, depending on the same parameter, i.e. the number of equipments. By total expenses we mean the expenses of the regular working time and the extra work costs. From the basis of the problem solving, it has already been indicated that the exploitation expenses in the regular working time for every vehicle are $t=200$ monet.units/day. Accordingly, the exploitation expenses in the regular working time, during one working week, can be calculated using the next formula:

$$
\mathrm{t}:=200 ; \quad \mathrm{d}:=5 \quad \Delta_{n}:=d \cdot t \cdot n
$$

By adding up these expenses, we get the total transport costs during one week, depending on the number of means. Those values are presented in the last table $\mathrm{T}-15$.

Table 15 Simulation of the cost

\begin{tabular}{|c|c|c|c|}
\hline $\mathrm{n}$ & $\Delta \mathrm{n}$ & $\mathrm{kn}$ & $\Sigma \mathrm{n}$ \\
\hline 1 & $1 \cdot 10^{3}$ & $4.475 \cdot 10^{3}$ & $5.560 \cdot 10^{3}$ \\
\hline 2 & $2 \cdot 10^{3}$ & $3.317 \cdot 10^{3}$ & $5.428 \cdot 10^{3}$ \\
\hline 3 & $3 \cdot 10^{3}$ & $2.159 \cdot 10^{3}$ & $5.207 \cdot 10^{3}$ \\
\hline 4 & $4 \cdot 10^{3}$ & $1.002 \cdot 10^{3}$ & $5.032 \cdot 10^{3}$ \\
\hline 5 & $5 \cdot 10^{3}$ & 113.324 & $5.311 \cdot 10^{3}$ \\
\hline 6 & $6 \cdot 10^{3}$ & 0 & $6.027 \cdot 10^{3}$ \\
\hline
\end{tabular}

The least, i.e. the minimum value of functions of the simulated expenses in this case is:

$$
\min (\Sigma)=5001.69 \text { monet.units. }
$$

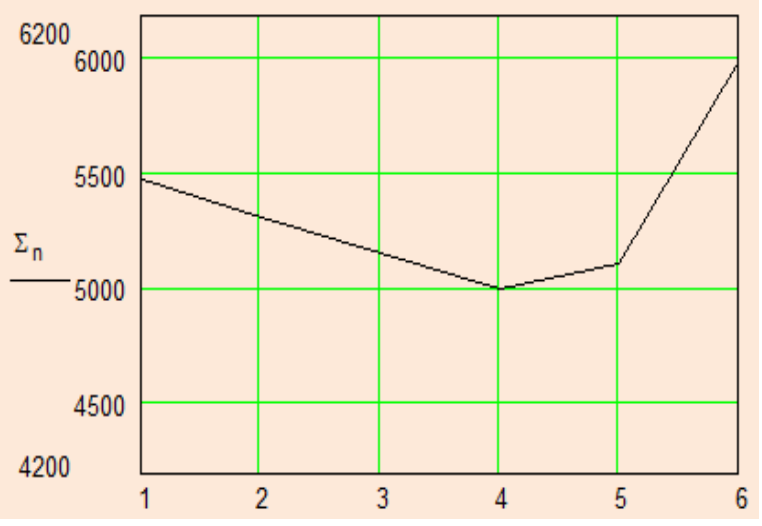

Figure 1 Diagram of the total transport costs

The data in this table show that in most cases the total transport expenses are the smallest in the variant when four means are engaged.The decision maker can even decide to use five means, so that he could have the reserve in the case of defect of some means or to avoid the extra work expenses, because they are, as it can be seen in the table (T-15), equal to zero, in the case when the work is done for six means. In this way we finished the simulation process as a computer experiment representing the scenario of the future transport situation. Besides in the tables, the results can also be shown graphically, as in the figure 1.

\section{CONCLUSION}

The simulation method presented by using the Monte Carlo technique proved itself as easy applicable on the chosen type of the transport problem. By using it we have experimented, i.e, considered many variants of the possible solutions, indirectly, on the model, not in reality, and thus greatly reduced the costs. During the consideration, the evidence of the events from the previous period was used, without alterations, because it was supposed that the situation in the plants was stable. However, some other options with different assumptions and limitations could have been set. The available information was general and subject to a specific form of distribution. It should be mentioned here that problems like the previous one can be considered on the basis of empirical data which don't have to be generalized and reduced to a mathematically-statistical form since the Monte Carlo method allows it. The reliability of the simulation depends on the size, i.e the dimensions of the replications. In the presented example the sample, although processed by computer, is very small and it wouldn't satisfy the demands of practice. The simulation could have been performed with more realizations, by simulating the demand and delivery during several months or years. Big samples could be processed by computer, using the random numbers vector and in more options. However, the goal of it was to enable better understanding of the studied process. We mustn't neglect the fact that simulation cannot provide the optimal solution as applying some of the mathematical methods can. We can consider this solution conditionally optimal. In fact, the solution which is not equal $n=4$ of transport means can appear in 
some replications. By the frame method, which can be applied in Mathcad (Letić, Berković, Davidović, \& Petrov, 2007), such case would be observed. But, the solution where $n=4$ is dominant in most cases. Anyway, the simulation enables analyzing the problems, developing the options and their comparison, but the work of defining the problems, setting the options themselves, their evaluation and decision making regards the selection of the optimal option should be done by an analyst - technologist.

\section{Works Cited}

Davidović, B. (2012). Unutrašnji transport - Intralogistika. Beograd: Intelekt.

Fishman, S. G. (1999). Monte Carlo concepts, Algorithms and Applications, Springer Series in Operations Research. Springer.

Kun, L. (1973). Primena istraživanja operacija. Novi Sad: Mašinski fakultet.

Letić, D., Berković, I., Davidović, B., \& Petrov, T. (2007). Mathcad 13 u matematici i vizuelizaciji. Čačak: Kompjuter biblioteka.

Letić, D., Davidović, B., Berković, I., \& Petrov, T. (2007). Mathcad 13 u matematici i vizuelizaciji. Čačak: Kompjuter biblioteka.

Pidd, M. (1998). Computer Simulation in Management science. Chichester, England: John Wiley \& Sons.

Radenković, B., Stanojević, M., \& Marković, A. (1999). Računarska simulacija. Beograd: FON.

Vukadinović, S., \& Popović, J. (1996). Metoda Monte Karlo. Beograd: Saobraćajni fakultet.

Received for publication:

Revision received:

Accepted for publication:
24.10.2013

26.11.2013

21.12 .2013

\section{How to cite this article?}

Style - APA Sixth Edition:

Davidović, B., Letić, D., \& Jovanović, A. (2014, 01 15). Monte Carlo simulation in intralogistics. (Z. Čekerevac, Ed.) MEST Journal, 2(1), 87-93. doi:10.12709/mest.02.02.01.09

Style - Chicago Fifteenth Edition:

Davidović, Branko, Duško Letić, and Aleksandar Jovanović. "Monte Carlo simulation in intralogistics." Edited by Zoran Čekerevac. MEST Journal (MESTE) 2, no. 1 (01 2014): 87-93.

Style - GOST Name Sort:

Davidović Branko, Letić Duško and Jovanović Aleksandar Monte Carlo simulation in intralogistics [Journal] = Monte Carlo simulation in intralogistics // MEST Journal/ ed. Čekerevac Zoran. Belgrade : MESTE, 01 15, 2014. - 1 : Vol. 2. - pp. 87-93. - ISSN 2334-7058 (Online); ISSN 2334-7171.

Style - Harvard Anglia:

Davidović, B., Letić, D. \& Jovanović, A., 2014. Monte Carlo simulation in intralogistics. MEST Journal, 15 01, 2(1), pp. 87-93.

Style - ISO 690 Numerical Reference:

Monte Carlo simulation in intralogistics. Davidović, Branko, Letić, Duško and Jovanović, Aleksandar. [ed.] Zoran Čekerevac. 1, Belgrade : MESTE, 01 15, 2014, MEST Journal, Vol. 2, pp. 87 93. ISSN 2334-7058 (Online); ISSN 2334-7171. 